\title{
Towards a New Data Economy for EU Agriculture
}

\begin{abstract}
This paper discusses the transformation from analogue to digital agriculture (smart farming) and the laws and regulations affecting the governance of agricultural data in the EU. It is argued that the current legal and policy framework in the EU is insufficient to serve the needs of responsible smart farming systems. Specific characteristics of farm data and patterns in farm data collection and use contribute to market failures in agricultural data markets and hence to the insufficient provision of public goods through agriculture. The key parts of the smart farming data value chain are shaped by private contractual agreements between farmers and agricultural technology providers that do not take into account the potential negative externalities of established data flows. There is a strong rationale for a new data economy for EU agriculture, implying a greater involvement of the state in the smart farming data value chain. Interventions would be needed both to support the ecosystem for datadriven innovations in farming and to minimize the risk of new economic and social inequalities in the agriculture sector. The creation of an EU-wide farm data repository under the auspices of EU institutions and integrating public agricultural data with private farmers' data subject to anonymisation and aggregation can be seen as a first step towards a new data economy for EU agriculture. Also, the Common Agricultural Policy should be more involved in and committed to the process of the digital transformation of farming in the EU.
\end{abstract}

Keywords: Agricultural Data, Responsible Smart Farming, Digitalization

\footnotetext{
^ Katarzyna Kosior - Institute of Agricultural and Food Economics - National Research Institute, Poland, e-mail: Katarzyna.Kosior@ierigz.waw.pl, ORCID: 0000-00034825-730X.
} 


\section{Introduction}

The rapid growth of information and communication technologies and the deluge of digital data in recent years have opened up new opportunities for economic development and social change. Digital technologies and the data revolution have also entered the agri-food sector. Modern agricultural equipment and new devices embedded with sensors have enabled automatic data collection on farms. The Internet of Things, cloud computing and machine learning algorithms have provided means for real or real-time data analytics to extract insights relevant for input use optimization and better management of natural resources at farm level. ${ }^{1}$ Not surprisingly, these technological advancements have changed the setting for agricultural data governance. Until recently, the public sector and public administration institutions were basically the principal actors engaged in collecting and aggregating larger amounts of agricultural data. Now, these processes also engage different private companies - agricultural technology providers, high-tech corporations, software developers, digital platforms and data engineers. On the one hand this provides new opportunities for data-driven decisions in farming, potentially leading to more efficient and more sustainable agriculture and food systems. On the other hand, however, specific problems and tensions in this area also emerge.

Unclear ownership and residual decision rights to agricultural data and privacy concerns related to the use of both personal and non-personal data collected on farms emerge as key regulatory challenges. ${ }^{2}$ Farmers are primarily concerned with potential misuses of any agricultural data collected on their farms. ${ }^{3}$ The same datasets that may inform and provide guidance in farming decisions may be also used by agricultural technology providers and data companies to improve their businesses and market position at the expense of farmers and rural communities. Since digitalization tends to lead to concentrated market structures, other concerns relate to the risks of agricultural data being concentrated in the hands of a few large companies. Such data monopolies might endanger both competition in the agri-food sector and the provision of some important

1 A. Weersink, Opportunities and challenges for Big Data in agricultural and environmental analysis, “Annual Review of Resource Economics”, No. 10/2018, pp. 19-37.

2 A. Ellixson, T. Griffin, Farm data: Ownership and protections, September 16, 2016.

3 See L. Wiseman, J. Sanderson, A. Zhang, E. Jakku, Farmers and their data: An examination of farmers' reluctance to share their data through the lens of the laws impacting smart farming, "NJAS-Wageningen Journal of Life Sciences", 8 May 2019. 
public goods through agriculture. The adoption of digital technologies by farmers is also uneven - either because some farmers lack the capital to purchase modern machines or do not have the adequate digital skills required to use data products and services, or both ${ }^{4}$ Moreover, economies of scale and scope tend to limit the market offer of data products and services to farmers. Therefore, although digital agriculture promises to make farming systems smarter, it might also lead to new social and economic inequality in rural areas.

While laissez-faire approaches to digital transformation tend to dominate in the world, the European Union attempts to establish a clear set of rules and regulations for the emerging digital economy. ${ }^{5} \mathrm{EU}$ institutions also have rich experience in agricultural data management. The collection of agricultural data in the Community had started even before the Common Agricultural Policy (CAP) was officially launched. Now, the CAP is one of the most complex systems of public intervention in agriculture in the world. It generates agricultural data and depends on agricultural data for proper operation. With new types of agricultural data collected through digital devices, farming systems in the EU and also the CAP could potentially become smarter and more efficient.

Although the EU framework for agricultural data governance is still in the making, it would be worth examining how and to what extent the existing and planned rules and regulations respond to the challenges, problems and tensions in the emerging smart farming data value chain. The aim of the paper is therefore to discuss the current policy and regulatory framework for the governance of agricultural data in the EU. Specifically, the paper will shed light on the EU's approach to agricultural data by examining relevant EU legislative acts and recent initiatives to establish a data economy within the Digital Single Market. The evaluation of the EU framework will be conducted against the background of the CAP's objectives to develop sustainable farming systems in Europe.

The paper is structured as follows. In the following second section a historical background to agricultural data management in the EU will be presented. The third section explains the transformation from

4 B.A. Aubert, A. Schroeder, J. Grimaudo, IT as enabler of sustainable farming: An empirical analysis of farmers' adoption decision of precision agriculture technology, "Decision Support Systems", No. 54(1)/2012, pp. 510-520.

${ }_{5}$ A Digital Single Market Strategy for Europe, Communication from the Commission to the European Parliament, the Council, the European Economic and Social Committee and the Committee of the Regions, $\operatorname{COM(2015)~} 192$ final, Brussels, 6.05.2015. 
analogue to digital agriculture, and specifically new sources and types of agricultural data. Emerging challenges and dilemmas in agricultural data governance are explained in more detail in the fourth section. The fifth section includes a critical evaluation of the current framework for agricultural data governance in the EU. The paper ends by discussing the need for regulatory intervention to ensure a new data economy for the CAP to serve the needs of responsible smart farming systems in the EU.

\section{Agricultural Data in the EU - A Historical Background}

Historically, the demand for agricultural data in the European Economic Community and later in the European Union was closely linked with and stimulated by the implementation and operation of the Common Agricultural Policy. The production, collection and storage of data concerning farmers, agricultural holdings, agricultural production, agri-food trade and rural areas was needed both to manage complex CAP support programmes and to monitor the progress towards the achievement of the CAP objectives.

The collection of data concerning agriculture and agricultural holdings in the EC/EU has been organized and managed through three major systems:

- The European Agricultural Statistics System (EASS) which has been developed since the early 1950s;

- The Farm Accountancy Data Network (FADN) established in the Regulation No 79/65/EEC in 1965;

- The Integrated Administration and Control System (IACS) set up by the Council Regulation (EEC) No 3508/92 of 27 November 1992, following the adoption of the MacSharry reform of the CAP.

Since the beginning, the EASS has been aggregating data from the input of national statistical institutes or other national statistical authorities of the EU Member States. ${ }^{6}$ Data collection and aggregation processes have been organized according to the specifications laid down in legal obligations. Datasets covering agricultural prices, needed for the management of common market organizations, were informed by nonconfidential prices for the most representative products as notified by Member States. Instead, the collection of data on agricultural holdings was organized with the use of the survey method. In 1994 the Community's agricultural information system was enriched with data coming from

${ }^{6}$ K. Tóth, Georeferenced agricultural data for statistical reuse, "Geosciences", No. 8, Vol. 188/2018, pp. 1-2. 
remote sensing. Data from this source were used to provide early estimates (i.e. before harvest) of acreages and potential yields of the main crops in the Community and for monitoring the development of rural areas. In 2000, aerial surveys were added to the EASS. Still, despite growing volumes of data, economic accounts of EU agriculture, published regularly by the Eurostat, have not been sufficiently informative to improve the assessment of the achievement of the CAP's objectives. ${ }^{7}$

FADN was established with the purpose of collecting the accountancy data needed both for determining farm incomes and for analysing the efficiency of agricultural holdings. Although the FADN data are not included in the EU statistics, they are closely linked to the EASS. Since the beginning, data for the FADN have been collected using national surveys on the annual sample of holdings providing the representation of market-oriented farms in the Community. Over the years, the FADN surveys have been also modified to reflect new demands and changes in the CAP. Specifically, new variables on the use of fertilizers in agricultural holdings have been added. Also, the information on subsidies granted to farmers has been updated. ${ }^{8}$ But, not unlike the EASS, the FADN has been criticized as not being sufficiently well designed for the purposes of the CAP's evaluation. ${ }^{9}$ Its basic limitation is that it covers only commercial holdings and income information is incomplete. There are also concerns raised regarding the quality of data used to measure farmers' incomes.

The third major system for collecting agricultural data in the EU, the IACS, was created as a follow up to the MacSharry reform of the CAP. The reform introduced direct payments into the CAP and hence created a need for a new system for managing and controlling farm subsidies to farmers in the Community. The IACS databases include records and data from each agricultural holding concerning aid applications, the amount awarded and all other relevant data needed for the proper management and control of direct aid schemes in the EU (i.a. geospatial data, comprising orthoimagery - geometrically corrected satellite images and aerial photographs of agricultural parcels).${ }^{10}$ Recent additions to the

${ }^{7}$ Is the Commission's system for performance measurement in relation to farmers 'incomes well designed and based on sound data?, Special Report No. 1/2016, https://www.eca.europa. eu/Lists/ECADocuments/SR16_01/SR_FARMERS_EN.pdf (access 9.09.2019).

8 EU Farm Accountancy Data Network 50 years of support for EU agriculture and farmers, Brussels, 16.06.2015, http://ec.europa.eu/agriculture/rica/50th_anniversary_ en.cfm (access 9.09.2019).

9 Is the Commission's system..., op. cit., p. 15.

${ }^{10}$ K. Tóth, Georeferenced agricultural..., op. cit., p. 2. 
IACS have included a reference layer to accommodate ecological focus areas and green payments introduced into the CAP in 2015.

Overall, the types of agricultural data gathered by EU institutions and the Member States have evolved over the years together with the evolution of the CAP. Initially, a particular focus was placed on data regarding agricultural prices, yields, production structures and import/export flows since price support system together with export refunds played a critical role in the management of common market organizations. However, along with the subsequent reforms of the CAP, new data domains have been added to the European agricultural statistics system, the FADN and the IACS. Now, the operation and management of the CAP requires a diversified array of data and information - spanning from data on agricultural markets, georeferenced data on agricultural parcels, data on area-linked aid schemes, to data and information on rural development and agri-environmental practices. ${ }^{11}$

This short historical overview shows that the EU agricultural statistics system and other related databases have grown tremendously over the past decades. Yet, as recent reports indicate, this has not significantly improved the CAP's performance. ${ }^{12}$ The inefficiencies in the system have been caused by both incomplete and missing information on some important aspects of the CAP's operation, and by the lack of interoperability between the systems for agricultural data collection. This has significantly limited the chances for exploiting potential synergies between the available data sources. Also, the reuse of agricultural data outside EU institutions has been limited. Particularly, farm advisory organizations and extension services, which by definition should base their work on agricultural data, have been using only a fraction of available data resources. By and large, the EU farm advisory system has been more focused on raising farmers' awareness about the CAP legal requirements (e.g. with regard to cross-compliance mechanisms concerning direct payments), rather than on advice regarding actual farm production and farm management. As agricultural data aggregators represented the public sector, there were little economic incentives to go beyond the tasks related to the CAP's implementation and monitoring. However, the current digital revolution fundamentally changes the models and ecosystems for agricultural data collection and use.

11 Commission Staff Working Document - Impact Assessment, accompanying the document, Strategy for Agricultural Statistics 2020 and beyond and subsequent potential legislative scenarios, SWD(2016) 430 final, Brussels, 9.12.2016.

12 Ibidem. 


\section{Digital Transformation in Farming - New Technologies, New Sources and New Types of Agricultural Data}

Recent years have seen a dramatic increase in the amount of data collected on farms. Specifically, new players from the private sector - agricultural technology providers, high-tech corporations and data companies - start to play an increasingly important role in the processes of collecting, storing, processing and analysing agricultural data. It is estimated that the amount of data generated per day by average farm exceeded 250000 data points in $2015 .{ }^{13} \mathrm{~A}$ further increase in agricultural data generation is forecast - from about 500000 data points per day in 2020 to more than 2000000 data points per day in $2030 .{ }^{14}$

This unprecedented surge in agricultural data volumes has been enabled by a combination of general purpose technologies and new digital tools and devices designed specifically for agricultural production and farms. With advances in ICT and the emergence of Internet of Things (IoT) it has turned out that agricultural data may be collected through sensors and other measurement devices almost continuously and in real time. In addition, in contrast to time-consuming surveys used in agricultural data statistics, digital data collected thorough IoT devices have proved efficient in providing very detailed and granular information on on-farm processes related to production, environment, animals, plant health etc.

Agricultural data gathered with digital tools and new technologies have been also more differentiated and more heterogenous, both in format and in type. Next to variables described by means of numerical values and stored in relational databases in the traditional row and column structure, agricultural databases have become increasingly filled up with unstructured and semi-structured types of data. These types of data include aerial images, maps, i.a. orthomosaics and field health maps, photos, videos, text messages and other qualitative measures describing or depicting events, processes and activities on farms and across agricultural fields. Depending on data collector policy and the character of data, some agricultural data are open public data to be used freely by interested parties, and other data are private, governed by private-law contracts and shared among the entitled parties. One should also mention other important sources and types of data such as posts and messages in social media and online platforms that allow multiple users to collaborate and to share information about agri-food markets,

13 A. Meola, Why IoT, big data \& smart farming are the future of agriculture, "Business Insider", 20 December 2016, https://www.businessinsider.com/internet-of-thingssmart-agriculture-2016-10?IR= $\mathrm{T}$ (access 10.09.2019).

14 Ibidem. 
prices, food demands and related developments affecting both farmers and other actors in the food supply chain.

The data revolution in farming and in broader economy has given rise to smart farming management information systems. Aggregated data from thousands of agricultural holdings can now be combined with relevant datasets comprising historical data on weather, soil conditions, soil moisture and cropping intensity in order to identify sources of specific problems (e.g. low productivity or plant diseases) and to predict them in advance. Smart farming management information systems may, in fact, offer various support tools from apps to help a farmer in their production decisions, with soil management and production insurance options to financial transactions and traceability in the agri-food chains.

\section{Challenges in Agricultural Data Governance for Smart Farming}

With new sources and types of data, agricultural data governance has become very complex, both in the EU and in other parts of the world. The collection, storing, processing, and use of agricultural data has been organized around an extensive and growing network of actors and organizations representing different interests and stakes. The actors and organizations active in this emerging new data economy for farming include commercial companies in the forms of: producers of agricultural equipment, seed and chemical corporations, digital tech giants, hardware and software providers, enterprises and start-ups offering data analysis services, farmers, trade unions, farm advisors, public sector institutions, non-profit organizations, universities, research institutes and innovation hubs. Agricultural data and systems for agricultural data management have always involved various organizations and actors, not always directly linked to farming or the agri-food sector. Yet, the extent of heterogeneity in the current network, and particularly the weight of players present in the network but active primarily outside the agri-food domain, is by no means unprecedented. This gives rise to specific concerns which can be exemplified by the words of Anthony van der Ley, President of CEMA, an organization representing European machinery manufacturers who said in an interview that "A company such as Google could have so much agricultural data at its disposal, originating from sensors, for example, that a company with that amount of information available could farm more effectively than $70 \%$ of current farmers". ${ }^{15}$

15 Digitalisation in agriculture is not simple, Future farming, 20 November 2018, https://www.futurefarming.com/Smart-farmers/Articles/2018/11/Digitalisation-in-agriculture-is-not-simple-361194E/ (access 4.09.2019). 
Although there is an increasing awareness that maximum openness and the sharing of data is a prerequisite to data-driven innovations in farming, it is also acknowledged that digital transformation might lead to new economic and social inequalities in the sector. ${ }^{16}$ One emerging problem is uneven adoption of smart farming technologies among farmers. The current network of organizations involved in agricultural data management and use operates under a quite fragmented and outdated regulatory framework. The absence of specific legal and regulatory frameworks around smart farming data leads to a lack of trust in the farming community and consequently inhibits farmers' willingness to share data. ${ }^{17}$ The regulation of smart farming, and the related agricultural data management is, however, difficult due to many interdependencies and complex linkages in the emerging smart farming networks. The disruptive character of digital technologies and the dynamic nature of ecosystems within which they evolve and operate have, in fact, created a host of new challenges for regulators.

Firstly, smart farming builds on digital datasets that can be easily copied and shared between all interested parties. The easiness of copying and sharing digital data increases the risks of unauthorized access and use of such data. Potential consequences include the violation of privacy rights, the manipulation of data and the causing of harm to the economic interests of data owners or other stakeholders. Conflict in this area is further exacerbated by the lack of a clear definition of property rights to different types of agricultural data. Generally, farmers are considered to be the owners of raw agricultural data collected on their farms, but aggregated datasets - which in fact allow for extracting new knowledge and insights important to farmers - are considered to be the ownership of companies and organizations engaged in collecting and aggregating data.

However, questions about full ownership rights, including residual ownership, are still raised since various activities and operations concerning agricultural data generation, collection, aggregation, processing, and analysis, have not been fully measured and valued in economic terms. Generally, under the current legal frameworks data aggregators (agricultural technology providers) seem to benefit disproportionately

${ }_{16}$ M. Kritikos, Precision agriculture in Europe. Legal, social and ethical considerations, Study - Science and Technology Options Assessment. Brussels, European Parliamentary Research Service, 2017, p. 18.

17 E. Jakku et al., If they don't tell us what they do with it, why would we trust them?' Trust, transparency and benefit-sharing in Smart Farming, "NJAS-Wageningen Journal of Life Sciences”, 17 December 2018, p. 7, https://doi.org/10.1016/j.njas.2018.11.002. 
more than data generators (farmers). ${ }^{18}$ This imbalance is regarded as socially unfair since in many instances the rapid growth of digital and tech companies has been enabled by an extensive user engagement and their work (as data generators). At the same time, many digital business models have also made use of the free access to some public data (e.g. satellite data) to develop new products and services.

Data collected on farms and aggregated into larger datasets can be considered as having some public good characteristics. Specifically, these data assets are critically important for informed food production decisions, global food security, the environment, public health and climate change policies. Nonetheless, some important parts of these data assets have been de facto monopolized in the private hands of a few large tech and digital companies. In addition, because private companies seek economies of scale they also tend to bias data collection towards larger farms and commercial agricultural holdings. With this being said, one should also note that the same mechanisms, and particularly the opportunity to capitalize on big data assets, have incentivised private companies to engage in developing innovative technologies and solutions for the agri-food sector. The following figure summarizes some fundamental tensions and dilemmas related to agricultural data governance and smart farming.

By and large, challenges to agricultural data governance for smart farming are multidimensional. If wider social aims and needs for public goods provision are taken into account, it becomes clear that state and public institutions should become more active in the emerging smart farming data value chains. The widest possible farm data repositories, integrating both public and private data, could provide a new boost to research and innovation in farming. ${ }^{19}$ Yet, the private sector companies would be primarily concerned with profit maximization when selecting the aims of their data analysis projects. Therefore, even if industry-level norms, rules and frameworks for responsible data analysis were to be developed, this might be not enough to manage many social and ethical concerns that arise in the area of smart farming. ${ }^{20}$ Hence the critical importance of adequate policy and legal frameworks for smart farming allowing for state support for data analysis projects furthering sustainable

${ }_{18}$ Cf. K. Bronson, I. Knezevic, Big Data in food and agriculture, "Big Data \& Society", No. 3(1)/2016, pp. 1-5.

19 Cf. M. Kritikos, Precision agriculture ..., op. cit., s. 52.

${ }^{20}$ Cf. C. Eastwood et al., Managing Socio-Ethical Challenges in the Development of Smart Farming: From a Fragmented to a Comprehensive Approach for Responsible Research and Innovation, "Journal of Agricultural and Environmental Ethics", pp. 1-28. 


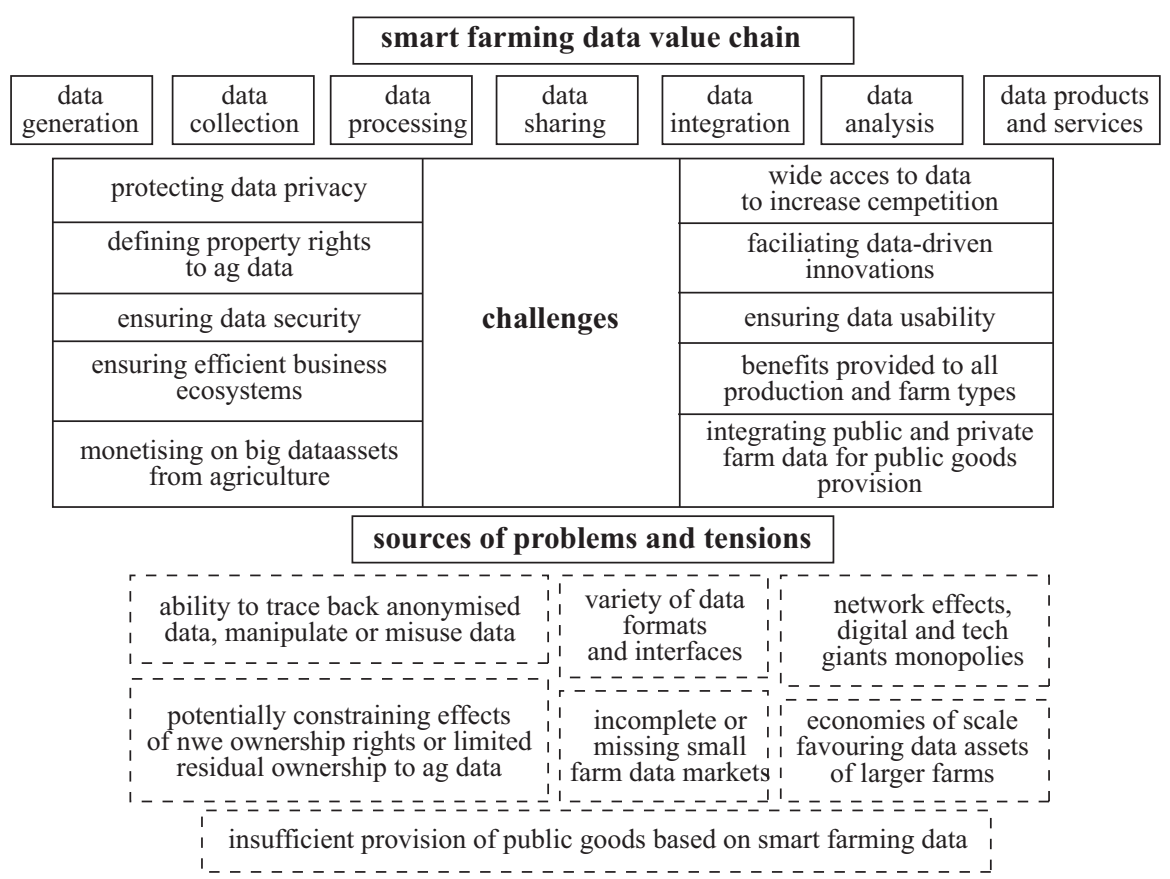

Figure 1. Regulatory challenges in agricultural data governance for smart farming

Source: own elaboration.

farming and food systems should be underlined. Against this background, policies, legal acts and regulations impacting smart farming and the digitalization of agriculture in the EU will be discussed in more detail.

\section{Smart Farming Data in the EU}

Although there are no separate CAP regulations or legal acts dealing with smart farming data in the EU, the last several years have seen many initiatives and legal work aimed at building the European data economy. Smart farming data forms part of broader digital data assets and it is therefore influenced by the agenda and horizontal regulations concerning the Digital Single Market. At the same time, as it is subject to different operations requiring the investment of human, technical and financial resources (including its collection, processing, structuring, and aggregation) it is also regulated by copyright law and the intellectual property regime. Therefore, legislation falling within these two remits impacts the current framework for the governance of smart farming data in the EU. Fundamental issues related to data flows, data use and its protection are currently dealt with 
by the EU Database Directive of 1996 and, in addition, two more recent regulations - the General Data Protection Regulation (GDPR) of 2016 and the Regulation on a framework for the free flow of non-personal data in the EU (FFNPD) of 2018. Smart farming is also influenced by specific EU policies, instruments and initiatives. The research and innovation policy and the CAP are two policies that have a clear impact on the pace and direction of the digitalization of agriculture in the EU. Last but not least, there are also agents from the EU agri-food chain who attempt to influence the governance of smart farming by propagating industry-level codes of practice and guidelines. Specifically, in April 2018 a coalition of associations including i.a. COPA-COGECA, CEJA, Fertilizers Europe and the European Agricultural Machinery, agreed on the EU Code of conduct on agricultural data sharing by contractual agreement.

The current EU framework for agricultural data governance, as defined by the legal acts, policies and initiatives mentioned above, is still incomplete and poorly adapted to deal with the challenges and needs of responsible smart farming. Moreover, some elements in the existing framework seem to increase tensions in the emerging digital-agriculture ecosystems. For example the EU Database Directive provides for a sui generis database right which means that if database creators establish that large investment was needed to obtain, compile and present the contents of the database, legal protection against unauthorized extraction and/or re-utilization of the whole or of a substantial part of the database created is provided. ${ }^{21}$ With no specific legal provisions concerning the ownership and protection of raw agricultural data, this enhances the position of agricultural technology providers and third party aggregators in the smart farming data value chain. Although some new initiatives and provisions in the realm of copyright law have been adopted recently, they basically address the problems and tensions outside the agriculture sector. ${ }^{22}$

The GDPR includes a set of provisions aimed at enhancing the protection, privacy and security of personal data in the EU. The Regulation defines "personal data" as any information relating to an identified or identifiable natural person ("data subject"). ${ }^{23}$ Individuals get the right

${ }^{21}$ Directive 96/9/EC of the European Parliament and of the Council of 11 March 1996 on the legal protection of databases, OJ L 77, 27.3.1996, pp. 20-28.

22 Such as the 2019 Directive on Copyright in the Digital Single Market that addresses the problem of unfair distribution of profits in the press and media sector between online content creators and the digital platforms.

23 Regulation 2016/679 of the European Parliament and of the Council of 27 April 2016 on the protection of natural persons with regard to the processing of personal data and on the free movement of such data, and repealing Directive 95/46/EC (General Data Protection Regulation), OJ L 119, 4.5.2016, 1-88. 
to have access to their personal data which is collected and processed by data controllers and data processors, to correct inaccuracies in their personal data, to give consent to the processing of their personal data for one or more specific purposes and to withdraw such consent or to have their data deleted. Personal data is to be processed lawfully, fairly and in a transparent manner. Data controllers have also been obliged to notify data subjects about any breaches of their personal data. Undoubtedly, the Regulation provides important legal standards and guidelines for the ethical use of personal data in a digital economy, but at the same time it may be hardly applicable to agricultural data. Most smart farming data is machine-generated and concerns soil, plants and animals. Although it may be linked with data on the profitability of specific production types or the GPS location to reveal important personal information such as farmers' income or farm location, its primary character is still nonpersonal. Therefore, a farmer may face difficulties when using GDPR rights to withdraw, for example, their consent to processing farm data collected on their farms with the use of machines and other devices as specified in a contractual agreement with an agricultural technology provider. This would be particularly true for data items subject to aggregation and anonymization procedures and presented in databases independently from datasets including personal data.

The regulation on the free flow of non-personal data aims to enhance competition on the EU's digital single market. It prohibits data localisation requirements imposed by Member States' public authorities for storing or processing of non-personal data. It also invites market actors to self-regulate by developing codes of conduct to allow users to switch between service providers without hindrance. ${ }^{24}$ The FFNDP is therefore an important step towards a data economy and may also boost the development of smart farming products and services. Potentially, with a more efficient business ecosystem for data storing and processing, prices for smart farming products and services could decrease. Yet, the regulation does not influence how and from which sources non-personal data is to be extracted and collected. The provisions of the regulation are focused on data portability and are basically limited to the processes and relations in the upper layers of the smart farming data value chain, i.e. layers involving companies and organizations engaged in data processing and storage. Therefore, although the established principle of the free flow of

${ }^{24}$ Regulation 2018/1807 of the European Parliament and of the Council of 14 November 2018 on a framework for the free flow of non-personal data in the European Union, OJ L 303, 28.11.2018, pp. 59-68. 
data may further innovate and expand the offer of smart farming products and services, they still may be restricted to specific types of farming or to the largest farms. Also, broader characteristics of non-personal data in farming, and particularly the fact that vast amounts of such data might be relevant for the provision of public goods have not been addressed in the FFNDP.

And yet, digitization and smart farming have recently been indicated as one of the main priorities of the future CAP. ${ }^{25}$ Greater integration of the CAP with research and innovation policy has also been proposed. Under the Horizon 2020 research programme, the EU has funded many innovative projects for using advanced digital technologies, artificial intelligence, robotics, Internet of Things and data-driven solutions in agriculture (i.a. Internet of Food and Farm, SmartAgriHubs or 4D4F) ${ }^{26}$ Still, however, the CAP - by primarily supporting the largest and the most mechanized farms - does not meet the needs of responsible smart farming systems. Because current CAP instruments focus on the largest farms, they de facto add to data market failures and contribute to the uneven adoption of digital products and services in European agriculture. In addition, the current policy framework does not provide means for combining large amounts of public data on agriculture (such as that gathered as a result of the farm support schemes' operation) with private data collected on farms with the use of new technologies. The most important databanks for the CAP - the EASS, FADN, IACS databanks - function independently from the growing volumes of smart farming data originated at farm level. In addition, key parts of the smart farming data value chain are shaped by private contractual agreements between farmers and agricultural technology providers that do not necessarily take account of the potential negative externalities of established data flows. Although the EU industrylevel code of conduct on agricultural data sharing promotes transparency and ethical business practices in agricultural data harvesting, collection and use, it does not address broader needs for developing sustainable smart farming systems in Europe. The CAP, as a sectoral policy, should therefore be more involved in and committed to the process of digital transformation of farming in the EU. This would require a new approach

25 The Future of Food and Farming, Communication from the Commission to the European Parliament, the Council, the European Economic and Social Committee and the Committee of the Regions“, $\operatorname{COM(2017)~} 713$ final, Brussels, 29.11.2017.

${ }^{26}$ EU Member States join forces on digitalisation for European agriculture and rural areas, 9 April 2019, https://ec.europa.eu/digital-single-market/en/news/eu-member-states-join-forces-digitalisation-european-agriculture-and-rural-areas (access 13.09.2019). 
to data economy in agriculture. Specifically, the CAP should include measures directed towards supporting digitalization and data production in agricultural holdings of various types and sizes. Particular attention should be paid to supporting digitalization and data production in smaller farms. Indeed, the policy itself should exploit publicly owned databanks along with aggregated and anonymised smart farming data collected from farmers or purchased from agricultural technology providers to a greater extent. With insights coming from expanded smart farming databanks, the realization of the CAP's objectives to develop resilient and sustainable farming systems in the EU and to support the delivery of public goods by EU agriculture would be more certain and effective.

\section{Conclusions}

Digitalization and digital tools generate a wealth of new data, information and knowledge that can benefit agriculture and food production. However, it is not clear as yet to what extent these benefits could be realized and how they would be shared among different actors in the agri-food chain. The current legal and policy framework in the EU is hugely lacking when it comes to serving the needs of responsible smart farming systems. There are however no clear answers or straightforward choices when it comes to regulating and managing the tensions and problems in the emerging smart farming data value chain. The EU takes an active stance and attempts to set ramifications and standards for the future digital economy, yet agriculture is among those sectors and industries that require additional rules and regulatory action. The EU regulations for data protection, data privacy and data flows are themselves important first steps towards establishing digitalised agriculture in Europe. Further interventions would be needed, however, both to support the ecosystem for data-driven innovations in farming and to minimize the risk of new economic and social inequalities in the agriculture sector. Without a specific strategy dedicated to the digitalization of agriculture, there is a risk that the concept of smart farming will benefit only selected groups of farms and specific types of farm production, which in effect might undermine the European model of agriculture. In this context, a need for substantial reforms of the CAP should be once again highlighted. Particularly, the system of direct payments should to a greater extent respond to the new challenges related to agricultural data production and use among different types of farms and different groups of farmers.

Until recently, the state was the most important collector of data on agricultural land, yields, farm production and profitability. In the EU 
particularly, vast amounts of agricultural data have been generated and collected as a result of the CAP's implementation. The historical overview of data management in the EU shows, however, that the use of agricultural data has been rather limited to administration and monitoring purposes. Not enough effort has been made to use the collected data to improve advisory services to farmers or to encourage innovation projects at farm level. Yet the current digital revolution fundamentally changes the settings for agricultural data governance. Private agricultural technology providers and digital tech corporations are becoming increasingly important players in the processes of harvesting, collecting and aggregating farm data. Specific characteristics of farm data and patterns in farm data collection and use seem, however, to contribute to data market failures and hence to the insufficient provision of public goods through agriculture. Therefore, there is a strong rationale for a greater involvement of the state in the smart farming data value chain. The creation of an EU-wide and publicly owned farm data repository, integrating public agricultural data with private farmers' data, but subject to anonymisation and aggregation, can be seen as a solution to supporting sustainable farming systems and the delivery of public goods by agriculture.

\section{References}

A Digital Single Market Strategy for Europe, Communication from the Commission to the European Parliament, the Council, the European Economic and Social Committee and the Committee of the Regions, $\operatorname{COM}(2015) 192$ final, 6.05.2015.

Aubert B.A., Schroeder A., Grimaudo J., IT as enabler of sustainable farming: An empirical analysis of farmers' adoption decision of precision agriculture technology, "Decision Support Systems", No. 54(1)/2012, pp. 510-520, DOI: https://doi.org/10.1016/j.dss.2012.07.002.

Bronson K., Knezevic I., Big Data in food and agriculture, "Big Data \& Society", No. 3(1)/2016, pp. 1-5, DOI: https://doi.org/10.1177/ 2053951716648174.

Commission Staff Working Document - Impact Assessment, accompanying the document, Strategy for Agricultural Statistics 2020 and beyond and subsequent potential legislative scenarios, SWD(2016) 430 final, Brussels, 9.12.2016.

Digitalisation in agriculture is not simple, "Future farming", 20 November 2018.

Eastwood C., Laurens K., Ayre M., Dela R.B., Managing Socio-Ethical Challenges in the Development of Smart Farming: From a Fragmented to a Comprehensive Approach for Responsible Research and Innovation, 
"Journal of Agricultural and Environmental Ethics", Vol. 32 (issue 130)/2017, pp. 1-28, DOI: https://doi.org/10.1007/s10806-017-9704-5.

Ellixson A., Griffin T., Farm data: Ownership and protections, September 16, 2016, DOI: https://doi.org/10.2139/ssrn.2839811.

EU Farm Accountancy Data Network 50 years of support for EU agriculture and farmers, Brussels, 16.06.2015.

EU Member States join forces on digitalisation for European agriculture and rural areas, Brussels, 9 April 2019.

Is the Commission's system for performance measurement in relation to farmers' incomes well designed and based on sound data?, Special Report No. $1 / 2016$.

Jakku E. et al, If they don't tell us what they do with it, why would we trust them?' Trust, transparency and benefit-sharing in Smart Farming, "NJASWageningen Journal of Life Sciences", DOI: https://doi.org/10.1016/j. njas.2018.11.002.

Kritikos M., Precision agriculture in Europe. Legal, social and ethical considerations, Study - Science and Technology Options Assessment, Brussels, European Parliamentary Research Service, 2017.

Meola A., Why IoT, big data $\mathcal{E}$ smart farming are the future of agriculture, "Business Insider", 20 December 2016.

The Future of Food and Farming, Communication from the Commission to the European Parliament, the Council, the European Economic and Social Committee and the Committee of the Regions, COM(2017) 713 final, Brussels, 29.11.2017.

Tóth K., Georeferenced agricultural data for statistical reuse, "Geosciences", No. 8(188)/2018, pp. 1-19, DOI: https://doi.org/10.3390/geosciences 8050188 .

Weersink A. et al., Opportunities and challenges for Big Data in agricultural and environmental analysis, "Annual Review of Resource Economics", No. 10/2018, pp. 19-37, DOI: https://doi.org/10.1146/annurev-resource-100516-053654.

Wiseman L. et al., Farmers and their data: An examination of farmers' reluctance to share their data through the lens of the laws impacting smart farming, "NJAS-Wageningen Journal of Life Sciences", DOI: https:// doi.org/10.1016/j.njas.2019.04.007. 